\title{
An Exploration of Indigenous Knowledge Related to Physics Concepts Held by Senior Citizens in Chókwé, Mozambique
}

\author{
Aguiar Muambalane Baquete ${ }^{a,}{ }^{,}$, Diane Grayson ${ }^{a}$ and Inocente Vasco Mutimucuio ${ }^{b}$ \\ ${ }^{a}$ Department of Physics, University of Pretoria, Private Bag X20, Hatfield 0028, South Africa; \\ ${ }^{b}$ Department of Mathematics and Science Education, Faculty of Education, Eduardo Mondlane University, \\ Mozambique
}

*CONTACT Aguiar Muambalane Baquete, email: Aguiar.baquete@uem.mz

\begin{abstract}
Indigenous knowledge is at risk of being lost in many parts of the world. It is important to find ways to preserve it for both cultural and practical reasons, since it is often well-suited to addressing local needs using available resources. If indigenous knowledge can be incorporated into school science curricula, it can also provide familiar contexts within which to learn scientific concepts, as well as helping the younger generation to recognise its value. The purpose of this study was to identify indigenous knowledge that could be related to physics concepts, with a view to integrating it into school curricula. Twenty-nine senior citizens from Chókwé, a rural village in Mozambique, volunteered to participate in two sets of in-depth interviews. The first set of interviews was individual and unstructured in order to explore which aspects of indigenous knowledge might be related to physics concepts. The second set was semi-structured and conducted in small groups in order to probe participants' understanding and application of the identified physics concepts. The results showed that participants had indigenous knowledge that was useful to them in their daily lives and that were applications of thermal physics, static electricity and mechanics concepts. In some cases participants' explanations were aligned to physics explanations, in some cases they were similar to students' alternative conceptions identified in the literature, and in other cases they referred to supernatural phenomena.
\end{abstract}

KEYWORDS: Indigenous knowledge, Curriculum, Physics concepts

\section{Introduction}

All knowledge is the product of human thought. The process of knowledge creation is influenced by the social context within which it occurs, which includes both cultural and intellectual norms. The status accorded to particular knowledge also depends on the social 
context, and is influenced by power relations among those who create and those who make use of the knowledge. In the case of scientific knowledge, the scientific revolution initiated a new form of knowledge creation and verification that many believe is universally accepted as objective, culture independent and representative of the highest form of logical reasoning.

There are others, however, who argue that what is commonly called 'scientific knowledge' is a cultural artefact of 'Western' culture, where 'Western' refers to Eurocentric, and includes countries outside Europe where the dominant cultural identity is derived from Europe, such as the USA and Australia (Dussel, 2000). Other forms of knowledge are then referred to as 'indigenous knowledge'. In countries where indigenous people are in the minority, such as Australia or the USA, indigenous knowledge is held by only a minority of the population. In African countries the vast majority of the population is indigenous. Nonetheless, African countries are increasingly adopting Western ways of thinking and embracing knowledge that has been created using them. Thus, even in African countries indigenous knowledge is becoming less widely known and valued, and is in danger of being lost (Msuya, 2007).

One of the reasons that indigenous knowledge is sometimes ignored or even refuted is that it may be seen to be at odds with scientific knowledge. However, indigenous knowledge often makes use of sound scientific principles, typically empirically derived, but not necessarily explained in conventional scientific terms. As with Western knowledge, some indigenous knowledge has been derived from systematic observations and experimentation, while other knowledge is formed in other ways, such as on the basis of religious beliefs or assertions by someone in authority. It is valuable to preserve such indigenous knowledge for both cultural and practical reasons, since it is often well-suited to addressing specific needs in local contexts using locally available resources (Das Gupta, 2011; Shaw, Takeuchi, Uy, \& Sharma, 2009).

From an educational perspective, the incorporation of indigenous knowledge into school curricula could have a positive effect on students' interest in science, while helping them to value and keep alive the indigenous knowledge of their grandparents (Kasanda et al., 2005 Ng'asike, 2011; Perin, 2011). Another motivation for incorporating indigenous knowledge into school curricula is to reduce the 'foreignness' that non-Western students may feel in science classrooms (Mashokod, 2014). Several authors (e.g. Aikenhead \& Lima, 2009; Webb, 2013) take a stronger position, arguing for a multi- and cross-cultural science curriculum, which rejects the domination of Eurocentrism principles in school science and seeks instead a holistic approach. Such an approach includes sociocultural, ethical, ecological and economic rewards for all students and citizens and utilises indigenous knowledge as the anchor to understanding nature. Aikenhead and Jegede (1999) note that one of the challenges for science curriculum designers and educational stakeholders in the twenty-first century is to develop culturally sensitive curriculum and teaching strategies.

In this study we report on interviews conducted with senior citizens in the rural community of Chókwé, Mozambique, in order to identify aspects of their indigenous knowledge that could be linked to physics concepts and incorporated into school curricula. 


\section{Method}

A convenience sample of senior citizens in the Chókwé District participated in the interviews. Chokwé was chosen because the first author comes from the area and can speak the local language, Shangaan. In addition, there has been little impact of Western modernisation on the community, with most people still following a traditional lifestyle and employing traditional practices. The first author worked through various levels of local authorities to gain access to the respondents. This was made easier by the fortunate coincidence of his visit and a government-sponsored open market day. In response to requests by the local leaders, 29 senior citizens, 18 women and 11 men, volunteered to participate in the study.

An ethnographic approach was used (Berg, 2004; Denzin \& Lincoln, 2005; Reeves, Kuper, \& Hodges, 2008). The local leaders assigned guides to the first author to help him find the location of the interviews-either respondents' homes or a public place agreed to by the local leaders in each of the six participating villages - and introduce him to the volunteers.

Two sets of interviews were conducted. First, in-depth, unstructured, individual interviews were conducted. At the beginning of the interview, respondents were asked to talk about their experiences from their childhood up to the present. Although the conversation was unstructured during such interviews, it had a direction (Harrell \& Bradley, 2009). Thus, the interviewer tried to listen for personal opinions and information that could be associated with physics concepts and phenomena, asking follow-up questions and requesting further elaboration. Issues related to other areas of science, such as health care and food security, also surfaced during the interviews, but were not pursued by the interviewer. The interview transcripts were analysed to identify those ideas that could be related to physics concepts.

The second set of interviews was semi-structured and conducted with nine groups of three or four of the initial respondents at a time. Respondents were asked questions about the indigenous knowledge that had been identified in the first set of interviews and linked to physics concepts in order to obtain further insight into how they understood and applied it. Areas for discussion, identified in the first set of interviews, were related to the thermal properties of building and cooking materials, steps in the production of African beer, and aspects of trapping and hunting animals and lightning. While the applications they discussed could often be linked to physics, in some cases the explanations were compatible with conventional physics explanations and in other cases they were not.

The interviews were conducted in Shangaan. Both sets of interviews were audio-recorded and transcribed. Following analysis based on narrative inquiry (Clandinin \& Connely, 2004; Hart \& Nolan, 1999), the first and third authors, who are Shangaan speakers, identified salient extracts of the interviews and translated them into English.

\section{Results}

During the course of the interviews, indigenous knowledge was discussed that could be related to thermal physics, mechanics and electricity concepts and phenomena. In the sections that follow, applications and respondents' explanations of these concepts will be 
presented and compared with conventional physics explanations. In the interview extracts ' $I$ ' refers to the interviewer, while each respondent is identified by means of a number followed by letters to indicate whether the conversation is about thermal phenomena (TP), electrical phenomena (EP) or mechanics concepts (MC).

\section{Thermal Physics}

In this section we present indigenous knowledge that relates to TP and properties, namely, thermal conductivity and insulation, thermal equilibrium, and evaporation and condensation.

\section{Thermal conductivity}

During the first round of individual interviews, it became clear that in Chókwé clay is widely used as a building material and for making various types of pots, storage containers and platters. Four common clay articles are Ihambethu for cooking, murringwé for storing water, kambane for serving food and xitseka for softening maize meal. The traditional house is made of sticks plastered with clay, both on the inside and outside. In the kitchen area, the sticks are left unplastered (Figure 1).

Figure 1. (a) The picture on the left shows a plastered main house on the left and lightly plastered kitchen on the right and (b) the picture on the right shows an unplastered kitchen.
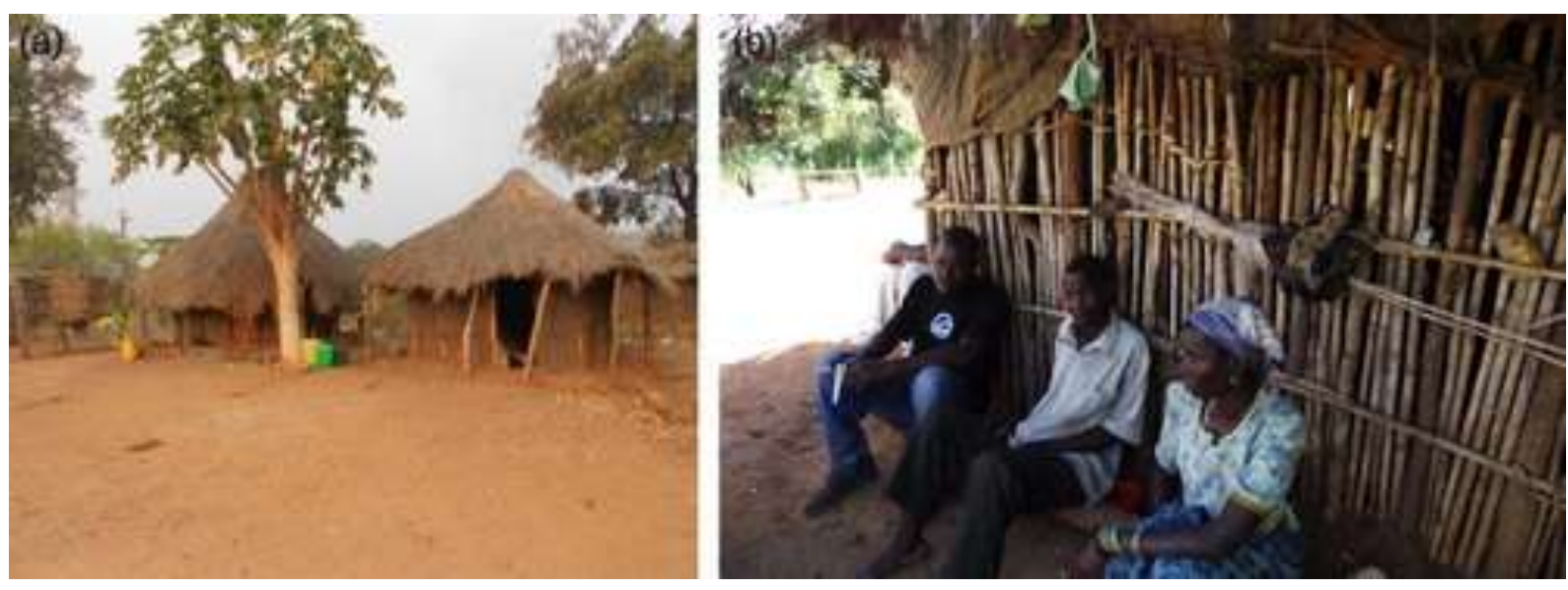

In the second round of interviews, the group interviews, respondents were asked about why they use clay to plaster their houses. Sample responses are shown below.

I: Why do you plaster traditional houses with clay?

1TP: Hum ... to keep it warm in the winter ... .and also not to be hot in the summer, even on hot days ... . while the kitchen isn't plastered ... we cook in the kitchen ... and sticks allow smoke to go out.

6TP: ... there are differences between inside and outside of a plastered traditional house ... clay protects inside of the house and doesn't allows hotness [ku ni mumu] or coldness [ku ni xirhami] to enter into the house. 
In Shaangan the meaning of a word sometimes changes according to the prefix and context. For instance, when explaining the role of clay in traditional plastered houses, some respondents referred to hotness [ku ni mumu] instead of heat [mumu] and they use the expression coldness [kumi ni xirhami] instead of cold [xirhami].

Another interview was done on a cool, rainy day. The responses of the group to the same question are shown below.

11TP: ... Hum ... I don't know ... this is our culture. We plaster our houses with clay ... a clay house is more comfortable ... you can feel it ... Go outside ... . Yes ... now, go outside. You can feel it yourself. Yes, go ... go. How do you feel? Is it the same?

I: No. Here, outside is cold, is not warm.

11TP: ... Today outside is cold and inside is not ... but ... on a hot day what happens is just the opposite ... Clay doesn't allow the coldness or hotness to enter inside.

15TP: ... inside of a house plastered with clay is not hot in summer ... hotness doesn't enter ... look today is cold but here [inside] is not ... clay doesn't allow coldness to enter inside .... .

I: Please. What does the clay really do in the traditional house? The clay blocks the entrance of coldness or keeps hotness inside of the traditional house?

11TP: ... yes ... the clay doesn't allow that coldness or hotness enters into the house. ... you are a Shangaan speaker ... if you need to hold something you need to possess it first. Or you can only keep things which are yours ... a thing that you already hold ... a thing that belongs to you.

The quotes above show that the respondents know from their experience that plastering their houses with clay makes them more comfortable in both hot and cold weather. They speak of 'hotness' and 'coldness', or heat and cold, as if they were substances that could flow through the walls. The effect of the clay is to block the flow of 'hotness' and 'coldness' into the building. These quotes indicate that the respondents have practical knowledge of the insulating properties of clay. Their notion of hotness and coldness as distinct entities or substances in motion, while different from the physics concept of heat transfer, has been identified in research on students' conceptions of thermal physics (Mutimucuio, 1998).

In addition, the comment from 11TP above illustrates the Shangaan understanding that it is only possible to 'keep' something that is in your possession, so traditional houses plastered with clay cannot 'keep' hotness or coldness, they can only block them.

In another group respondents were asked whether they prefer to use a metal or a clay cooking pot (Figure 2). Interview extracts related to this question are shown below.

I: Why do you prefer to use a clay pot rather than a metal pot when you prepare your meals? 
4TP: I grew up using a clay pot ... and good cooking requires a slower boiling. How to do it in a metal pot? When we use a clay pot sometimes we remove fire wood and the pot remains boiling ... you can't do it if you are using a metal pot ... .

I: It is true that even without firewood the clay pot [contents] continues boiling?

4TP: Yes ... it is. Because clay pot holds heat [Lhambethu yikhoma ndzilo] ... it is not like a metal pot ... .

2TP: ... a clay pot has ability to retain heat ... when we remove the fire wood or the fire is off the boiling does not abruptly stop as in metal pot.

13TP: ... when we cook with a clay pot ... even if the fire wood finishes ... clay pot remains boiling ... while a metallic pot stops ... .

20TP: ... After cooking if you leave food in a clay pot it remains hot for a long period ... but the same does not happen with hot food in a metal pot because metal pot doesn't retain heat.

Figure 2. (a) On the left is a metal cooking pot and (b) on the right is a clay cooking pot.
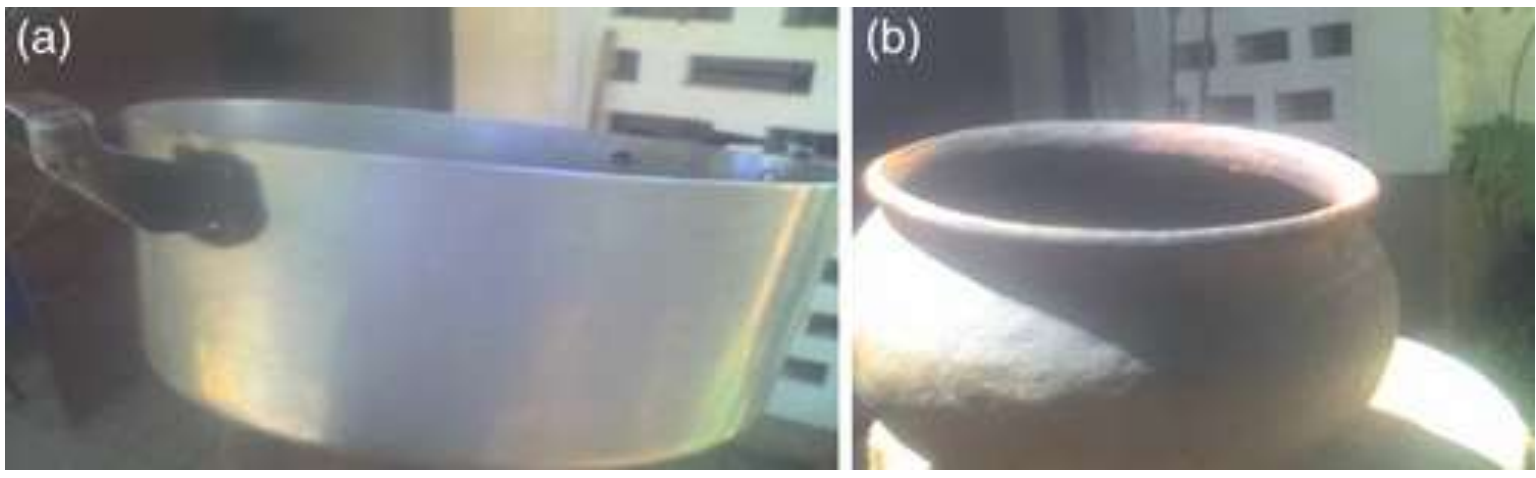

It should be noted that in the Shangaan language heat is referred to as mumu or ndzilo (fire). Respondent 4TP uses the latter term to designate heat. The interview extract above illustrates that respondents have a practical knowledge of the low thermal conductivity of clay compared to that of metal. The Shangaan concept of only being able to keep or hold something that you already possess is evident in quote 4TP-while the plastered wall could not 'keep' heat or hotness, the clay pot that was heated over the fire can. This understanding is also shown in the quote below from a different group:

17TP: ... After being heated the clay pot keeps heat ... if you remove the fire wood while the pot is boiling the clay pot will remain boiling for a longer period than if you remove the fire wood from a metal pot.

Practical knowledge of the low thermal conductivity of clay, as well as of the fact that heat flows from a hotter object to a cooler object, is illustrated in the following extract related to a traditional container used to serve food, kambane. 
25TP: Kambane is our container ... it has a secret ... you need to heat it up before placing food in it ... otherwise it will not perform properly ... . food will not remain hot for so long.

I: Why do you need to heat up before use it?

27TP: ... ha ha.ha ... before you place food into a kambane you need to heat up the container because you will place hot food ...... after placing food into the kambane you need to heat it up again in order to get the same temperature [swadjuleka kuva ulhela u hysseta khambane kuva swakudja ni khambane swita hyssakuvana]. ... .if you do not heat it up kambane will not perform properly. Consequently the hot food will cool faster.

Respondents were also asked about other cooking implements they used.

I: Besides clay and metal pots, which implements do you use to cook?

21TP: Meaning to mix food? ... The perfect instrument for cooking food is wooden spoon ... when you cook you cannot burn your hand.

17TP: ... another problem of using a metal spoon is related to time required for 'our food' ... you cannot cook any traditional food using this spoon ... because any wellcooked food requires a long period of time with the spoon in the pot mixing hot food. Because of that a metal spoon will become hot ... .

22TP: ... Yes ... I hate to use any metal utensils, spoon or pot, when I cook ... I always use clay pot and wooden spoon ... well-cooked food takes time in the fire and a metal spoon will burn your hand.

The extract above shows a practical knowledge of the low thermal conductivity of wood relative to metal, as well as knowledge that heat flows from the hot food through the cooking utensil to the hand. This knowledge is confirmed in the extract below, following a question in which respondents were asked if wood never burns their hands.

17TP: ... Can burn if you leave the wood spoon over a pot for long time ... even wood can burn .... .

I: Why do you say that a metal spoon can burn your hand and not refer to the fact that a wooden spoon can also burn?

21TP: ... ha..ha..ha ... you never cooked ... just dip a metal spoon in the hot water or hot food it becomes immediately hot ... but the wooden spoon not. The respondent, 17TP, explained everything. 


\section{Condensation and evaporation}

Chókwé is a very humid place, so condensation of water vapour is often observed, although it is not clear that respondents understand that the condensation they see is water. In the interview extract below the respondents compare a traditional house, which has a thatch roof, with a contemporary adaption that has a roof made of zinc sheeting.

13TP: ... If one carefully observes the typical traditional house you can see that there are spaces between the roof and walls ... through these open spaces the house breathes ... we leave these spaces for the house to breathe ... because peoples' breath will go outside through these spaces ... traditional house is not a closed house ... even if you close the door it continues breathing through those spaces ... people who use zinc they close all open spaces between the roof and the wall and the house is no more able to breathe ... it starts to sweat ... is a sign of not comfort, being comfortable? ... [Hamby wena loko noku Pfala nomu ni thynonphu unka sungula ku bhahla].

4TP: ... At night when people are asleep they close the door and windows. Thus, there is low air circulation consequently low ventilation in a house ... the warm air from peoples' breath mixes with the houses' air ... .as a result the house sweats.

2TP: ... traditional plastered houses covered by zinc are very hot in summer and cold in winter ... at night most of the time they drip water.

This extract shows that the respondents are familiar with the phenomenon of condensation when people are in a closed room on a hot night. Two of the above respondents say the house 'sweats', while the third one specifically says that the liquid formed in the house is water. The first two may know that the liquid is water and are using the term 'sweat' colloquially, but it is not clear from the transcript. Another use of the word 'sweat' to describe condensation is shown in the extract from the same interview below. It should be noted that clay pots used for storing water are sealed so that they are not porous.

13TP: ... Clay vessels cool water better than other materials ... Murringwé [water storage vessel made of clay] should be put in the shade. Clay becomes cool and water also becomes cool. ... Anytime the water will be cool ... Murringwé is our freezer ... which is made of clay. When the water is cool murringwé is sweating.

I: How do you know that water in the murringwé is cool?

20TP: ... when murringwé is sweating it means that the water (liquid) inside is cool.

While the respondents are correct in implying that the outside of the container gets wet when the liquid inside is cool, the fact that water is condensing on the outside of the container means that heat is being transferred to the container, not away from it, since water vapour releases heat when it changes phase and becomes water. However, the low thermal conductivity of the clay means that the clay prevents the water from heating up as much as it would if it were stored in something made of a material with higher thermal 
conductivity, such as a metal or plastic container. There may be some confusion here with evaporative cooling, in which heat is removed from an object when water molecules in contact with it absorb heat and change phase into water vapour. Evaporative cooling is used in the making of traditional African beer, which can be called uputsu, mahéu or ngovu in Chókwé. African beer is made from a mixture of cooked cereals to which a fermenting agent is added. The mixture must not be allowed to get too hot or else it will explode. The quotes below, from the same group interview, show how evaporative cooling is used to slow down the fermentation process.the fermentation process.the fermentation process.

the fermentation process.

I: What can you do in order to avoid the explosion of African Beer (uputsu; mahéu, ngovu)?

24TP: If the inside of the container is too hot the fermentation will not be normal ... will be faster ... to reduce the speed of fermentation in a metal container you need to cover the container with a wet material ... but if you use plastic you need to add an extra amount of cool cooked cereals ... .

7TP: There are different strategies ... to reduce speed of African beer's fermentation ... you can wet the external part of the container with cold water ... you can wet sacks or any material and cover the container with African Beer [mahéu] ... in order to cool the container ... but the best thing is to make a hole in the ground and put the container into the hole and wet it with water ... thus it will reduce the speed of fermentation ....

Another member of the group added:

5TP: There are different procedures to reduce the speed of fermentation ... the techniques vary according to the container ... if you use a clay or metal container you need to make a hole and fill it with water ... but it is important to guarantee air ventilation .... .

The reasoning presented by the respondents above allows us to conclude that they know that a hot body can be cooled down by wrapping or surrounding or covering it with wet clothes or wet sand. The explicit mention of the need for the material to be wet indicates that they have practical knowledge of evaporative cooling. This is supported by 5TP's response, in which she says that ventilation is also necessary. The respondents' awareness of different thermal conductivities of different materials is evident in their references to different procedures that are used with different container materials. In addition, 5TP appears to have practical knowledge of the higher specific heat capacity of water than air, which enables it to absorb more heat per unit mass per degree temperature change.

\section{Electricity}

In this section we present indigenous knowledge related to EP. Since most of the respondents live in homes with no electricity, their experience is mostly with lightning, 
which is extensive because Mozambique has a high frequency of lightning strikes. Given the frightening and devastating effects of lightning, including both human and animal deaths, it is not surprising that lightning is traditionally associated with supernatural forces (Dziva, Mpofu, \& Kusure, 2011).

The respondent quoted below spoke about how he knows that a storm is coming:

I: How do you know that heavy rain is coming?

9EP: ... There are different signs which announce heavy rain. One of them is Kwangulo. An abrupt change of weather and it quickly becomes cold. This change is caused by a chaotic motion of dark, gray and even white clouds associated with intense winds, lightning and thunder. Sometimes the heavy rain occurs with hailstones. Kwangulo is also characterised by strong winds and hailstones.

Another respondent in a different interview expanded on these ideas:

7EP:

... Two important phenomena announce that heavy raining is coming ... Kwangulo and Xidzindza. ..I am very afraid of xidzindza because it is an intense lightning and strong thunder [ku hatima gophu kulhela kuba thilo hi thamo ... ] which emit a loud sound ... [ku dzindza].

I: Please can you tell me more about lightning?

7EP: ... There is lightning and thunder ... clouds ... when .....when ... it is raining or starts to rain we ... .have a thunder ... clouds are colliding ... thunder [Ku ba thilo ... ku dzindza] and lightning [Ku hatima].

I: Sorry. Are there differences between thunder and lightning?

7EP: ... hum ... yes ... thunder is clashing of clouds ... and lightning ... lightning ... is a stone with fire which is falling down somewhere.

The loud sound associated with thunder leads the respondent to think that there is a clashing of clouds in the sky, commonly called Ku ba thilo, which can be understood as knocking in the heavens. This is probably the source of the conception which links thunder with a clash or collision between clouds. The idea that lightning contains a 'stone' was mentioned in several interviews, for example:

21EP: Lightning is a charged stone ... full with fire ... when it falls down it can burn everything, houses, trees ... animals and even humans ... when it falls it is important to dig it up and remove this stone otherwise this stone will attract other lightning ....

In group interviews, respondents discussed safety around lightning. Respondent 3EP referred to measures that should be taken in order to avoid being hit by lightning: 
3EP: ... it is very dangerous to be in water ... ride a bicycle ... use a silver-coloured watch ... these things ... attract lightning ... .we need to avoid rivers, beaches or any concentration of water ... because, lightning can strike you at any moment ... .lightning is attracted by water.

Similar ideas were raised by respondent 25 in a different group:

25EP: This phenomenon is dangerous ... I hate lightning because you need to avoid many things ... you need to switch off the radio ... to not be under ...trees ... .hum ... hum ... .

trees ... hum ... hum ... .

I: How do the rivers, silver-coloured materials, trees and radio attract lightning?

25EP: hum ... these things happen because they are able to attract ... there is another object ... a mirror also attracts ... how these objects attract lightning I don't know. ... Have you ever used a mirror? ... How does your image appear in the mirror?

The respondents quoted above have practical knowledge of the dangers of being in water during an electrical storm, but think that water attracts lightning, as opposed to providing a conducting path for the lightning. On the other hand, trees and other tall objects can be thought of as 'attracting' lightning in that charge is likely to be attracted up them from the ground in response to the electrostatic field created by charge separation in the clouds. It is not clear what link the respondents see between lightning and shiny, metal objects (Dos Santos Silva, 2007; Trengove \& Jandrell, 2011).

As mentioned earlier, many people think that lightning can be affected by supernatural forces (Baquete, Grayson, and Mutimucuio, 2009; Keul, Freller, Himmelbauer, Holzer, \& Isak, 2009; Petrus, 2011). This is illustrated in the following interview extract:

17EP: ... There are people who use lightning to kill others ... even without clouds ... when somebody sends it the lightning strikes you ... .only you ... even if we are ten people ... this lightning will hit you alone ... . these witches are dangerous ... they exist ... .

21EP: There is lightning coming from clouds in rainy days ... which can be attracted by rivers, lakes, sea, tall trees, water over roads ... white clothes, but ... also there is other lightning, very dangerous, ... which is ... guided by people ... most times, used to show power or kill people ... it can strike you ... anywhere ... human lightning ... that can occur even without clouds and can hit you even when you are among other people ... it is caused by witchcraft ... these witches are dangerous ... .

Similar ideas were raised in another group:

3EP ... there are different types of lightning. The natural one comes together with thunder but there exist other guided by some people ... that one can occur even without clouds ... but any lightning is dangerous. 
In addition to evil supernatural forces that can send lightning to kill people, some people believe that there are good supernatural forces that can neutralise lightning, as illustrated by the quote below from one interview:

5EP: ... There are healers ... real healers who know how to remove the stone of the lightning. Currently few people know how to remove it ... some know but they are afraid of problems ...... then the one who knows the secret just use it to protects his/her belongings, house animals ... Personally I know some plants which move away the lightning ... is just a plant ... a natural plant.

The reasoning from the respondent above suggests that lightning is a ball of fire or a stone charged with fire.

\section{Mechanics}

During the interviews indigenous knowledge related to force, addition of forces, levers, pressure, surface tension, conversion of elastic potential energy to gravitational potential energy or kinetic energy and impulse was identified.

\section{Applied forces}

In Chókwé men traditionally haul a barrel by pulling it with a rope over their shoulders, while women tie the rope around their waist. The women quoted below explain why.

5MC: When we pull a barrel we tie a rope around the waist and ... not to the shoulders ... The barrel is pulled in the waist zone ... and our hands are free. ... we never use the shoulders to pull barrels ... only a man does it.

I: Why do you prefer to pull the barrel by the waist instead the shoulders?

7MC: ... I need to have my arms free in order to help me to balance my body and have more strength ... .

5MC: ... Most of the time we pull the barrel and we carry a baby [on the back] or something else on the head ... also if we use shoulders we can injure our breast ... because we should press the rope down on our shoulder and press it into our chest.

While having their hands free, their babies on their backs and protecting their breasts are all practical reasons for women to tie a rope around their waist instead of across their shoulders, it also makes good physics sense, since there will be a larger component of force in the direction of motion and the women therefore need to exert a smaller force in order to do the same work on the object they want to move. Figure 3 shows a sketch of this situation. 
Figure 3. A man (left) and a woman (right) pulling a load.

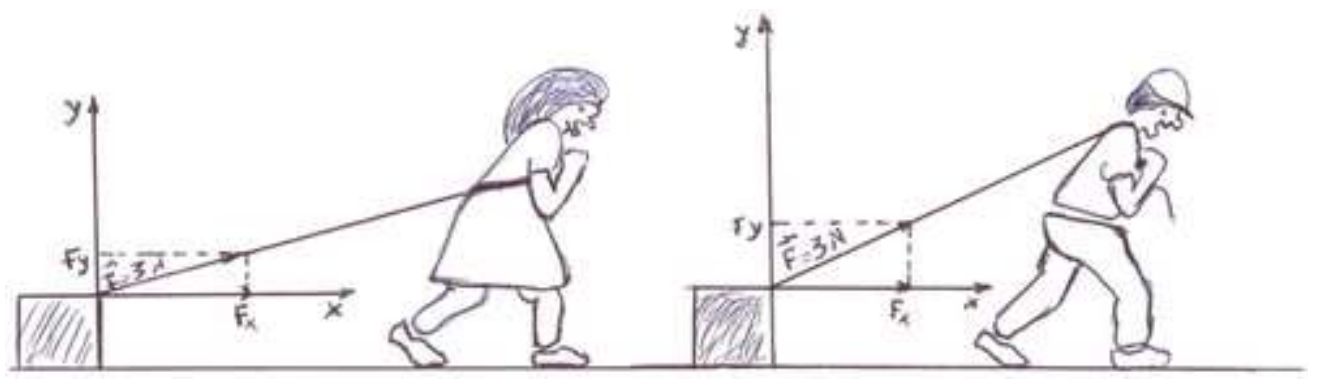

A traditional fish trap used in Chókwé is called a xisseka (Figure 4). Once the fish swim into it they cannot escape. If the number of fish in the trap is great, it may take more than one person to haul it out. The interview extract below shows practical knowledge of the superposition of forces.

13MC: ... In the fishing activity we use various tools. For instance one is made of sticks and ropes and is called xisseka, which is placed in the river or lake ... if you are not able to pull it out alone from the river you need to call other fishermen ... two hands exert more force than one.

The quotation below shows practical knowledge of levers in the use of a hoe.

8MC: On the farm we use long handled hoe ... here, in Chókwé, the soil is clay ... which is very stiff ... only the long handled hoe is useful, the other hoe ... with short handle is not efficient here ... it is used in soft sand ... not here.

Figure 4. Picture of a traditional fishing basket called xisseka taken during in-depth interview in Chókwé District, Mozambique, 2007.

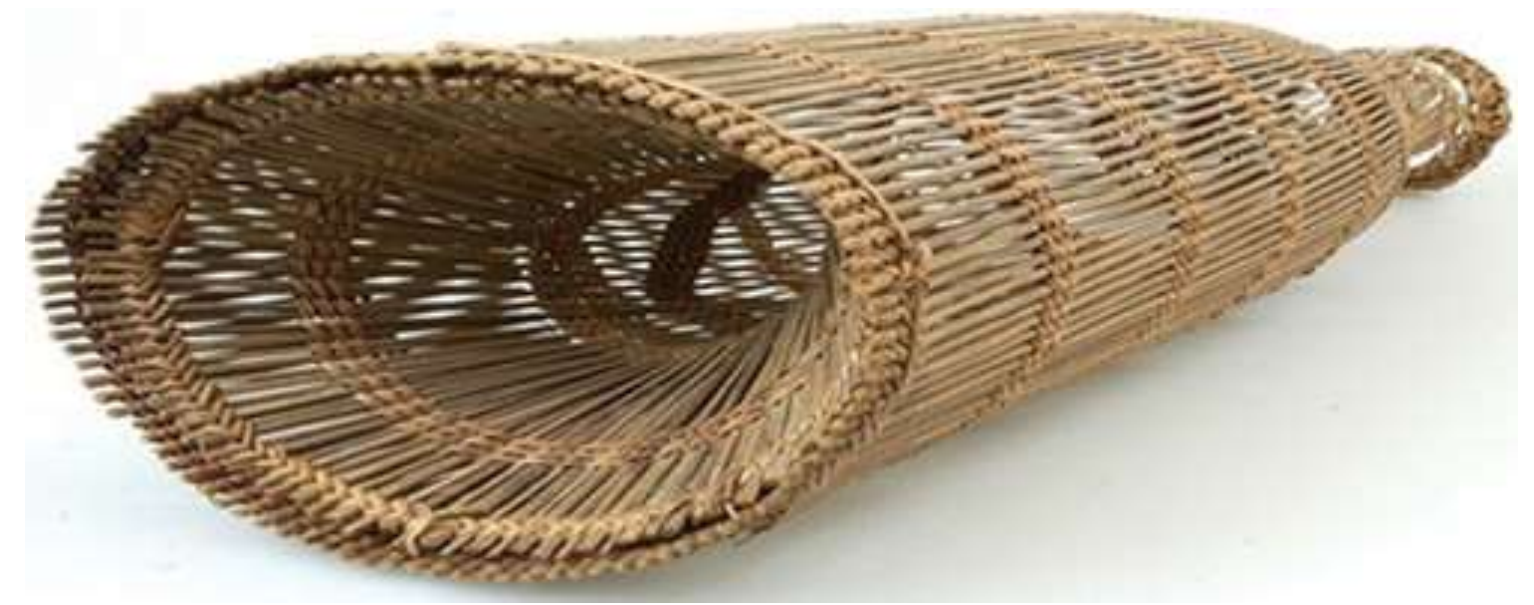




\section{Pressure and surface tension}

The quotations below indicate that the respondents have practical knowledge of the pressure created by the gas produced during fermentation of African beer, as well as of surface tension.

9MC: ... you cannot close any container with African Beer ... otherwise the container will explode ... .In order to avoid the explosion we keep it open ... if you want to close it you might use tree leaves ... leaves make holes on the surface of the liquid. Through these holes beer 'breathes' ... also through leaves the container will spill a little and the container doesn't explode.

29MC: ... in addition to wetting the surface of the container ... it is important to dip a long wooden spoon to crack the surface of liquid ... and keep it open ... this procedure is important otherwise the beer will explode ... through the crack on the surface the African beer will breathe.

\section{Energy transformations and impulse}

In the interviews respondents also described different techniques used when they hunt, specifically with traps and arc bows (Figure 5).

Figure 5. A traditional arc bow.

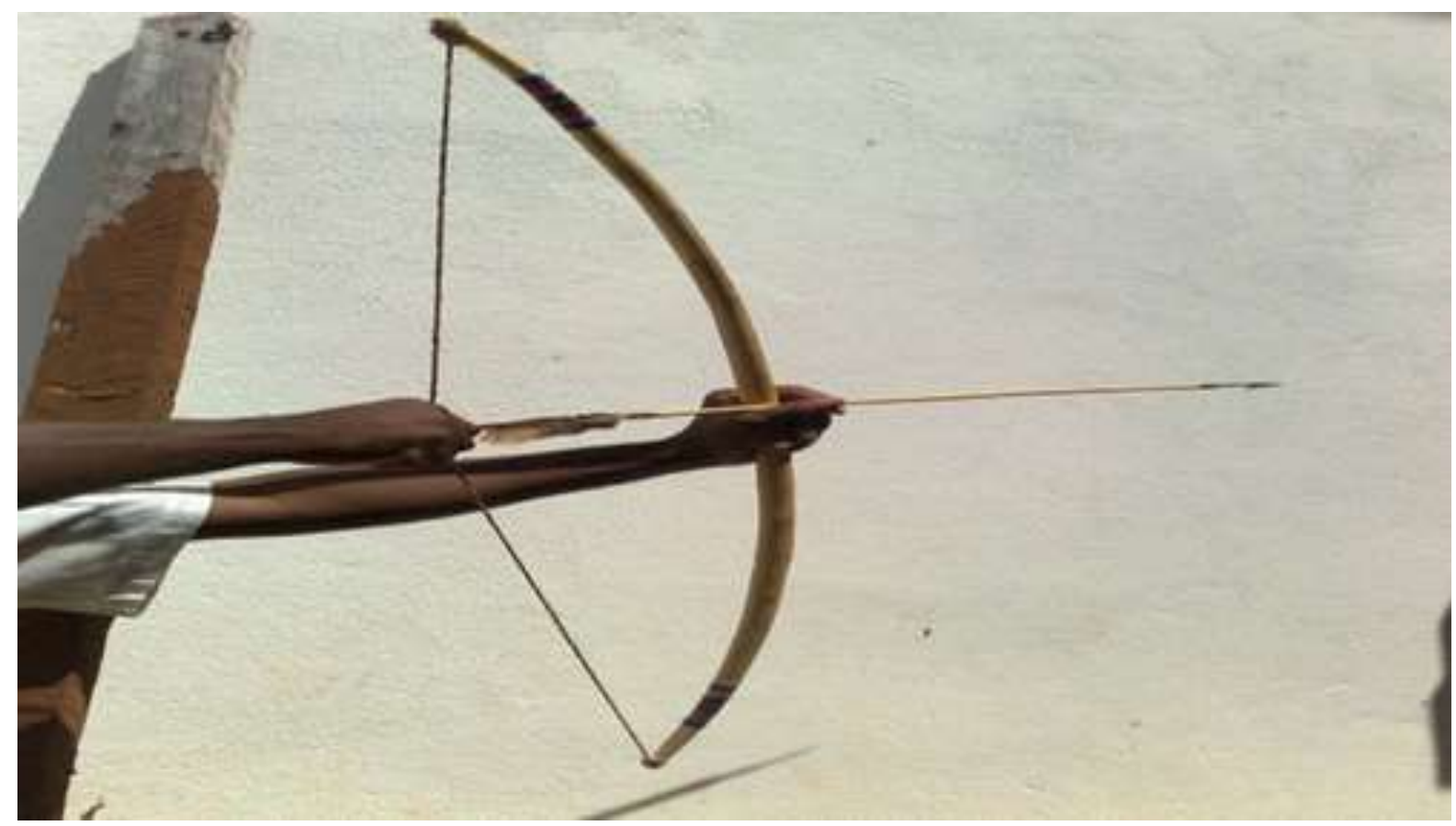

During the discussions they revealed knowledge associated with energy transformations, as shown in the following interview extract.

I: How do you make a trap? 
3MC: Traps are made by ropes and a flexible tree. The tree is bent ... and it should be sufficiently strong in order to hold the animal's weight ... The trapped animal should be suspended without touching the ground.... if a trapped animal finds any supporting point it can use its strength and break the tree or break the rope.

8MC: ... we use traps, which are made of flexible sticks which are bent by a thin rope and tied ... but we also use arc bows, ... these tools are flexible sticks which are bent and tied with a rope at the end points.

19MC: ... The arc bow must be strong but the rope must be flexible because it needs to push the arrow ... if you pull it right a gazelle or antelope should be killed.

The quotations above suggest that the respondents have practical knowledge of how elastic potential energy can be converted to gravitational potential energy (in a trap) or kinetic energy (in a bow and arrow). There is also a suggestion of practical knowledge of impulse, as when an animal kicks the ground and is able to break the tree or rope used for the trap.

\section{Conclusion}

In this paper we have identified a number of examples of indigenous knowledge that are related to physics concepts. In most cases, there is a good alignment between the physics and the respondents' 'practical knowledge', by which we mean their use of the concepts in their everyday lives in ways that can be explained using physics concepts. However, not surprisingly, their explanations of the phenomena are not generally aligned to standard physics explanations. For the most part, the explanations can be characterised as common sense. In some cases these explanations mirror common-sense explanations found in other cultures, such as the idea of 'hotness' or 'coldness' that moves between objects initially at different temperatures. In addition, certain phenomena were explained in terms of supernatural forces.

The identification of physics-related indigenous knowledge has the potential to raise awareness of indigenous knowledge and its value in society at large. For example, more people would benefit from it if they were to build their houses using the traditional approach of thatching the roof and leaving an air gap, rather than living in a stiflingly hot, metal-roofed house with no ventilation because it is perceived to be modern and therefore better. Given that this knowledge is based on scientific principles and derived from experimentation and observations, we would prefer to call the knowledge that the local people display about heat, for example, as physics knowledge generated by indigenous people.

From a pedagogical perspective, the identification of indigenous knowledge that can be related to physics concepts provides an opportunity for science curriculum developers to incorporate examples of physical phenomena that are familiar to students, thereby providing a valuable link between school science and everyday life (Belleau, Ross, \& Otero, 2012; Coştu, 2008; Ng \& Nguyen, 2006). However, when explanations of these phenomena are discussed, teachers will need to employ appropriate conceptual change strategies if students, like the senior citizens, engage in common-sense reasoning (Chigeza \& 
Whitehouse, 2014). On the other hand, Baquete (1998) claims that when scientific explanations differ epistemologically from cultural explanations, as in the case of the causes of lightning, much more nuanced conversations between teachers and students will be needed in order to ensure cultural sensitivity. For instance, teachers could challenge the validity of the indigenous knowledge that some people control lightning and lead learners to explore the source of such knowledge. The need to embrace both Western and indigenous knowledge as ways of knowing is well articulated by Barnhardt and Kawagley (2005, p. 10):

Recently, many Indigenous as well as non-Indigenous people have begun to recognize the limitations of a mono-cultural education system, and new approaches have begun to emerge that are contributing to our understanding of the relationship between indigenous ways of knowing and those associated with western society and formal education. Our challenge now is to devise a system of education for all people that respects the epistemological and pedagogical foundations provided by both indigenous and western cultural traditions.

\section{Disclosure statement}

No potential conflict of interest was reported by the authors.

\section{Funding}

This work was supported by (Swidish International Development Agency, SIDA) [Programme 7: Developing Research Capacity in Education].

\section{References}

Aikenhead, G. S., \& Jegede, O. J. (1999). Cross-cultural science education: A cognitive explanation of a cultural phenomenon. Journal of Research in Science Teaching, 36(3), 269287.

Aikenhead, G. S., \& Lima, K. E. C. (2009, November 8-13). Science, culture and citizenship: Cross-cultural science education. A keynote paper presented to the VII national conference on research in science education (VII ENPEC), Florianópolis, Santa Catarina.

Barnhardt, R., \& Kawagley, A. O. (2005). Indigenous knowledge systems and Alaska native ways of knowing. Anthropology and Education Quarterly, 36(1), 8-23

Baquete, A. M. (1998). Influence of mother tongue (Chope) on teaching and learning in science education: A Mozambican study about fundamental electrical concepts (Unpublished Masters dissertation). University of the Witwatersrand.

Baquete, A. M., Grayson, D., \& Mutimucuio, I. V. (2009). Probing indigenous knowledge related to Physics concepts amongst senior citizens in Chókwé, Mozambique. Poster presented at the World Conference on Physics Education, Bangkok, Thailand, 18-24 October. 
Belleau, S. N., Ross, M. J., \& Otero, V. K. (2012). Implementation of physics and everyday thinking in a high school classroom: Concepts and argumentation. 2011 physics education research conference. AIP Conference Proceedings 1413, 127-130. doi:10.1063/1.3680010.

Berg, B. L. (2004). Qualitative research methods for the social science (5th ed.). Long Beach: California State University, Pearson. ISBN 0-205-37906-2.

Chigeza, P., \& Whitehouse, H. (2014). Incorporating indigenous students' cultural knowledge more productively in mathematics and science classrooms: One focus for pre-service teacher education research and practice. Leadership in Indigenous Research Special Issue, etropic 13.1, 45-53.

Clandinin, J. D., \& Connely, M. F. (2004). Narrative inquiry: Experience and story in qualitative research. San Francisco, CA: Jossey-Bass.

Cos, tu, B. (2008). Learning science through the PDEODE teaching strategy: Helping students make sense of everyday situations. Eurasia Journal of Mathematics, Science \& Technology Education, 4(1), 3-9.

Das Gupta, A. (2011). Does indigenous knowledge have anything to deal with sustainable development? Antrocom. Online Journal of Anthropology, 7(1), 57-64.

Denzin, N. K., \& Lincoln, Y. S. (2005). IIntroduction: The discipline and practice of qualitative research. In N. K. Denzin \& Y. S. Lincoln (Eds.), The handbook of qualitative research (3rd ed., pp. 1-32). Thousand Oaks, CA: Sage.

Dos Santos Silva, E. (2007). A Física dos Relâmpagos e dos Raios [The physics of thunderstorms and rays] (Unpublished Masters dissertation). Catholic University of Brasília, pro-rector's office of graduate studies, Brasilia.

Dussel, E. (2000). Europe, modernity and eurocentrism. Position papers. Nepantla: Views from South 1.3, Duke University Press.

Dziva, D., Mpofu, V., \& Kusure, L. P. (2011). Teachers' conception of indigenous knowledge in science curriculum in the context of Mberengwa district, Zimbabwe. African Journal of Education and Technology, 1(3), 88-102.

Harrell, M. C., \& Bradley, M. A. (2009). Training manual. Data collection methods. Semistructured interviews and focus groups. RAND National Defense Research Institute. Retrieved from http://www.rand.org.

Hart, P., \& Nolan, K. (1999). A critical analysis of research in environmental education. Studies in Science Education, 34(1), 1-69. doi:10.1080/03057269908560148

Kasanda, C., Lubben, F., Gaoseb, N., Kandjeo-Marenga, U., Hileni Kapenda, H., \& Campbell, B. (2005). The role of everyday contexts in learner-centred teaching: The practice in Namibian secondary schools. International Journal of Science Education, 27(15, 16), 18051823. 
Keul, A. G., Freller, M., Himmelbauer, R., Holzer, B., \& Isak, B. (2009). Lightning knowledge and folk beliefs in Austria. Journal of Lightning Research, 1, 28-35.

Mashokod, D. (2014). Indigenous knowledge for plant medicine: Inclusion into school science teaching and learning in Zimbabwe. International Journal of English and Education, 3(3), 528-540. ISSN: 2278-4012. Retrieved from http//:www.ijee.org

Msuya, J. (2007). Challenges and opportunities in the protection and preservation of indigenous knowledge in Africa. International Review of Information Ethics, 7. Retrieved from http://www.i-r-i-e.net/inhalt/007/38-msuya.pdf

Mutimucuio, I. V. (1998). Improving students' understanding of energy: A study of the conceptual development of mozambican first-year university students. Amsterdam: VU Huisdrukkerij.

$\mathrm{Ng}$, W., \& Nguyen, V. T. (2006). Investigating the integration of everyday phenomena and practical work in physics teaching in Vietnamese high schools. International Education Journal, 7(1), 36-50. ISSN 1443-1475. Retrieved from http://iej.cjb.net 36

Ng'asike, J. T. (2011). Turkana children's rights to education and indigenous knowledge in science teaching in Kenya. New Zealand Journal of Teachers' Work, 8(1), 55-67.

Perin, D. (2011). Facilitating student learning through contextualization community (CCRC Working Paper No. 29). College Research Center, Teachers College, Columbia University. February.

Petrus, T. (2011). Defining witchcraft-related crime in the eastern cape province of South Africa. International Journal of Sociology and Anthropology, 3(1), 1-8. Retrieved January 2011, from http://www.academicjournals.org/ijsa. ISSN 2006-988x.

Reeves, S., Kuper, A., \& Hodges, B. D. (2008). Qualitative research. Qualitative research methodologies: Ethnography. BMJ, 337, a1020. doi:10.1136/bmj.a1020[CrossRef], [PubMed], [Web of Science ${ }^{\circledR}$ ]

Shaw, R., Takeuchi, Y., Uy, N., \& Sharma, A. (2009). Indigenous knowledge (Disaster_risk_reduction. Policy note). European union european union, international strategy for disaster reduction, Kyoto University And Seed.

Trengove, E., \& Jandrell, I. R. (2011). Strategies for understanding lightning myths and beliefs. IJRRAS, 7(3). June, 2011. www.arpapress.com/Volumes/Vol7Issue3/IJRRAS_7_3_08.pdf

Webb, P. (2013). Xhosa indigenous knowledge: Stakeholder awareness, value, and choice. International Journal of Science and Mathematics Education, 11, 89-110. ISSN 1571-0068. doi 10.1007/s10763-012-9370-z[CrossRef], 